\title{
Experimental study of the tribological characteristics of a honed cylinder liner during the running-in process
}

\author{
Jianxiong Kang ${ }^{1,2}$, Yanjun $\mathrm{Lu}^{1,2}$, Bin Zhao ${ }^{1}$, Cheng Jiang ${ }^{1}$, Pengzhou $\mathrm{Li}^{1}$, Hongbo Luo ${ }^{1}$, and \\ Yongfang Zhang ${ }^{2,3}$ \\ ${ }^{1}$ School of Mechanical and Precision Instrument Engineering, Xi' an University of Technology, \\ Xi'an 710048, PR China \\ ${ }^{2}$ State Key Laboratory for Manufacturing Systems Engineering, Xi' an Jiaotong University, \\ Xi' an 710049, PR China \\ ${ }^{3}$ Faculty of Printing, Packaging Engineering and Digital Media Technology, Xi' an University of Technology, \\ Xi'an 710054, PR China \\ Correspondence: Yanjun Lu (yanjunlu@xaut.edu.cn)
}

Received: 17 August 2021 - Revised: 9 November 2021 - Accepted: 11 December 2021 - Published: 17 February 2022

Abstract. The tribological properties of the cylinder liner are of great significance in reducing energy loss from an internal combustion engine's system. In order to improve the antiwear performance of the cylinder liner at top dead center (TDC), the friction and wear of the honed cylinder liner during the running-in process are investigated. Using a UMT TriboLab multifunction friction wear tester, the coefficients of friction (COFs) are analyzed under different lubrication conditions and loads, and the surface roughness and profile of the cylinder liner are obtained using a three-dimensional (3D) laser scanning confocal microscope (LSCM). The COF, roughness and surface profile are compared in order to investigate the variation in tribology parameters under different operating conditions. To monitor the $\mathrm{COF}$ in real time, it is predicted using the polynomial fitting method. It is shown that the COF decreases with an increase in the lubrication oil and load and that the surface profile more easily becomes smooth under dry (lubrication) conditions; this can effectively shorten the operation time during the running-in process. The polynomial fitting method can achieve an assessment of the COF with a very small standard error.

\section{Introduction}

As the main equipment of large ships and power generation systems, the development prospect of internal combustion engines (ICEs) has attracted great attention in recent years. The piston ring-cylinder liner (PRCL) system is one of the most important parts of high-performance ICEs, and the energy loss caused by friction and wear of the PRCL accounts for more than $50 \%$ of the total energy loss, greatly reducing the power conversion efficiency and service performance of ICEs (Tomanik et al., 2018; Biberger et al., 2017). Wear of the cylinder liner decreases power and reliability, and severe wear may lead to major accidents. In order to improve the energy conversion efficiency and to reduce emissions, the antifriction and antiwear technology as well as the tribological characteristics of the PRCL system have become a hotspot and nodus in engine design and manufacture.

The tribological characteristics of the PRCL system are linked with factors such as lubrication, material, surface quality and coatings. Lubrication can effectively reduce friction and wear, and many scholars have investigated lubrication characteristics in order to improve the antiwear performance of the system. In order to reduce friction and wear, calcium sulfonate and an organic antiwear additive have been blended into lubricant to study the wear of the PRCL system, and a large-scale friction film has been produced on the contact surface (Burkinshaw et al., 2013). As an engine additive, liquid boron has been used to improve the lubrication properties of the engine, and the wear performance has been found to be significantly improved compared with an engine without additive lubricating oil (Ogut et al., 2019). With the de- 
Table 1. The technical parameters of the multifunction friction and wear tester.

\begin{tabular}{lr}
\hline Parameters & Values \\
\hline Linear velocity & $0.1-50 \mathrm{~mm} \mathrm{~s}^{-1}$ \\
Frequency & $0-50 \mathrm{~Hz}$ \\
Temperature & $-25-1000^{\circ} \mathrm{C}$ \\
Load & $0.1-1000 \mathrm{~N}$ \\
Displacement & $1-150 \mathrm{~mm}$ \\
\hline
\end{tabular}

velopment of new materials, many nano-materials have also been applied to improve the lubrication performance (Asnida et al., 2018; Javeed et al., 2021). To reduce the friction and wear rate, cellulose nanocrystals have been used as a green additive to improve the tribological properties of the PRCL under different operating conditions (Awang et al., 2019). Lubricating oil additives can effectively reduce friction and wear; however, the lubrication mechanism of additives is difficult to describe quantitatively. Thus, in order to reveal the friction and wear mechanisms of the PRCL, researchers have established numerical models to investigate wear under different lubrication conditions. A flow model has also been established to analyze lubrication performance under different engine operating conditions (Sun et al., 2019). Moreover, a dynamic numerical model of the piston and lubrication has been presented, and the influence of the thermal effect on lubrication has been considered (Hamid et al., 2018). By taking the oil film thermal effect, the cavitation phenomenon and surface roughness into account, the effects of compression ring wear and cylinder liner deformation on mixed lubrication and tribological performance have been studied (Liu et al., 2018, 2019). Due to the characteristics of friction and wear, the surface topography of the PRCL has a great influence on the antifriction and antiwear characteristics. Considering the surface technology and lubrication conditions, the tribological properties (surface texture, mixed lubrication, surface roughness and wear) of the PRCL system have been studied for different contact surfaces (Guo et al., 2013; Usman and Park, 2016, 2017; Zhang et al., 2018a). Most of the abovementioned studies have investigated the effects of lubrication and surface quality on wear performance using modeling and numerical simulation. However, the wear of the PRCL system is influenced by different factors during the operation process, and its tribological behaviors are complex. Therefore, the reciprocating sliding testing method is widely used to study friction and wear of the PRCL system.

The tribological experiment has become one of the important technical methods to investigate the friction experienced by the PRCL. The surface topography parameters have a significant impact on friction and wear, and the effect of the cylinder liner surface topography on abrasive wear has been studied at different honing settings (Michalski and Wos, 2011). Research on the surface texturing of the cylinder liner
Table 2. The evaluation parameters of the coefficients of friction (COFs) under different loads.

\begin{tabular}{lrr}
\hline Load & $200 \mathrm{~N}$ & $300 \mathrm{~N}$ \\
\hline$a$ & 0.106 & 0.106 \\
$b$ & $6.64 \times^{-4}$ & $-1.30 \times^{-7}$ \\
$c$ & $-4.96 \times^{-11}$ & $2.38 \times^{-11}$ \\
$d$ & $1.55 \times^{-15}$ & $-7.08 \times \times^{-16}$ \\
\hline
\end{tabular}

has attracted more attention with respect to reducing friction (Babu et al., 2020; Walker et al., 2019), and the wear rates of the cylinder liner have been studied at different engine speeds, loads and cylinder rotation angles (Musmar et al., 2019). Meanwhile, the influence of the lubrication conditions and temperature on wear and friction of the PRCL has been studied using a reciprocating test (Obert et al., 2016). Due to complex forces and lubrication conditions, the friction and wear of the PRCL increase sharply, and surface coating technology can effectively improve the tribological performance of the system. To investigate the effect of the coating on wear, hard and soft coatings have been applied to piston rings, and the effects of the variation in the coats on the wear rate have been investigated (Kumar et al., 2018). In addition, the PRCL has been coated with $\mathrm{CrAl}_{2} \mathrm{O}_{3}$ and diamond-like carbon in order to improve the surface performance, and it has been found that the surface finishing process can decrease the friction coefficient and wear loss; thus, the scuffing resistance of the system is improved (Ma et al., 2019; Ferreira et al., 2021).

The friction and wear of the honed cylinder liner have been investigated by many scholars (Kim et al., 2018; Liu et al., 2018). However, there are few experimental studies on the friction and wear of the PRCL at top dead center (TDC), especially for the honed cylinder liner and coated piston ring during the running-in process. Therefore, in this work, tribological testing of the coated piston ring and honed cylinder liner is designed to investigate the friction and wear of the cylinder liner at TDC. The coefficient of friction (COF) and surface profile are analyzed using a UMT TriboLab multifunction friction and wear tester and a three-dimensional (3D) laser scanning confocal microscope (LSCM), and the effects of different lubrication and load conditions on roughness parameters are investigated. In order to shorten the test time and costs, a predictive model of the COF under different operating conditions is proposed. By testing and analyzing the friction and wear of the PRCL at TDC, the wear characteristics are explored. 

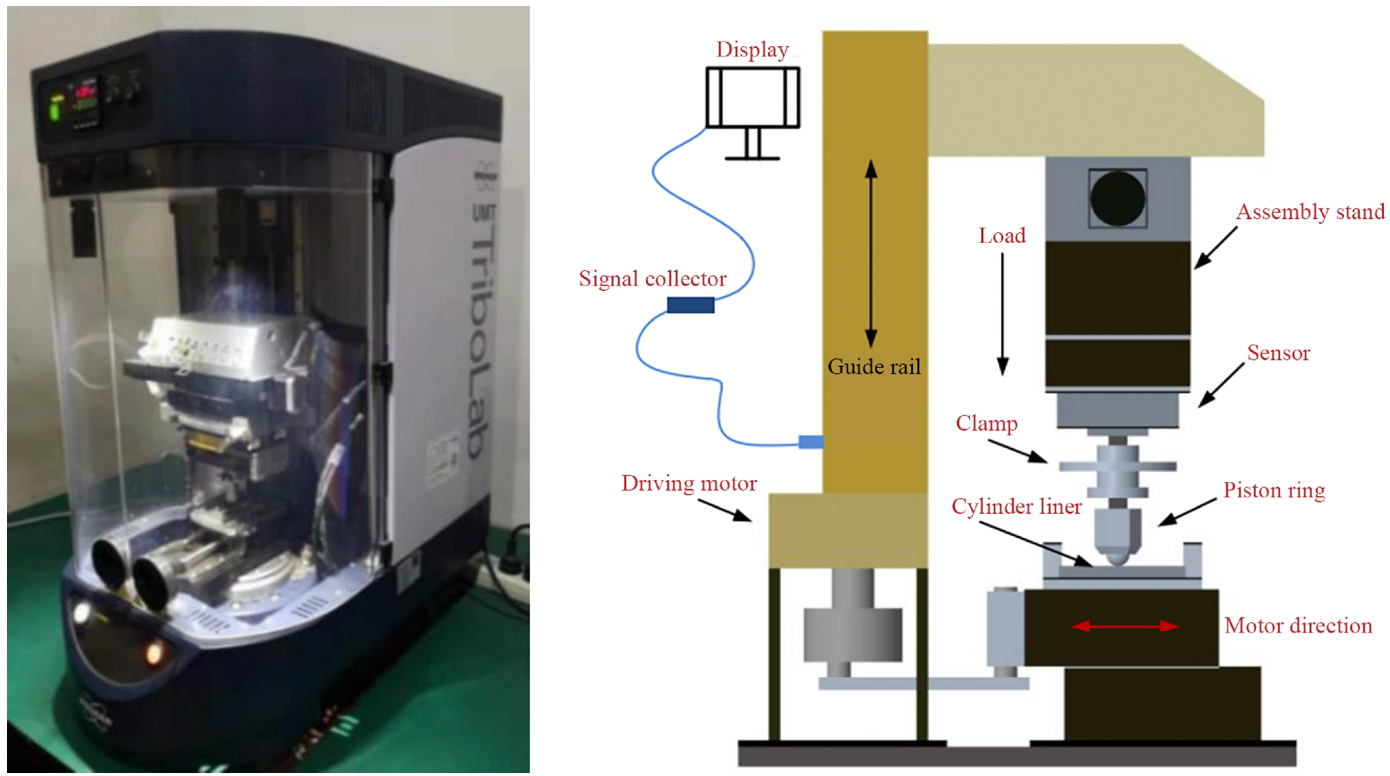

Figure 1. A photograph of the UMT TriboLab multifunction friction and wear tester as well as an outline of its structure.
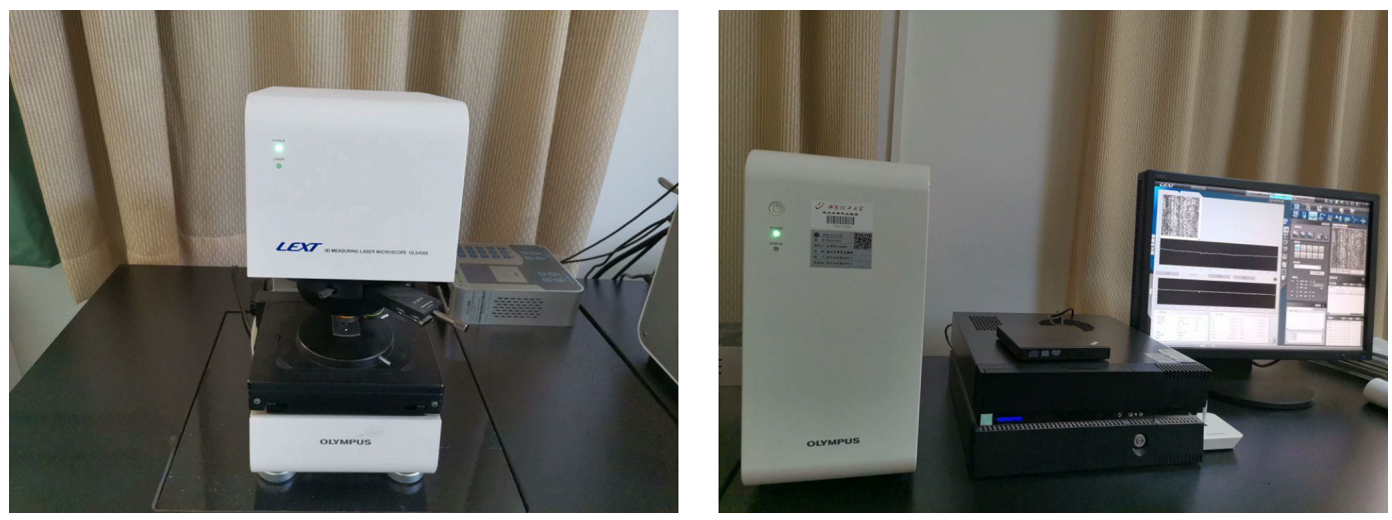

Figure 2. The 3D laser scanning confocal microscope (LSCM).

\section{Experiments}

\subsection{Experimental apparatus}

The UMT TriboLab multifunction friction and wear tester are the most widely used instruments in its class. It can simulate the multiple movements of the friction pair due to its unique modular design. A dual-channel force sensor is used to collect and record the vertical load and horizontal friction to the computer, and the relationship between the COF of the sample surface and time can be obtained. In order to improve the accuracy, high-sensitivity sensors are used in the UMT TriboLab tester. The resolution of the vertical stroke is $0.5 \mu \mathrm{m}$, the resolution of the horizontal stroke is $0.25 \mu \mathrm{m}$, and the accuracy of the positioning is $1 \mu \mathrm{m}$. Due to the good performance of the laboratory bench, it is used to investigate the friction and wear of the PRCL under different operating conditions. To simulate the motion of ICEs, the piston ring and

cylinder liner are processed into fresh slices, and the reciprocating motion module of the testing machine is applied to obtain the COFs and the wear samples of the cylinder liner. In order to improve the testing efficiency, the reciprocating stroke is set to $4 \mathrm{~mm}$. This can satisfy the measurement range of the LSCM, which is $16-2560 \mu \mathrm{m}$. The working principle of the wear tester is shown in Fig. 1, and the technical parameters are listed in Table 1.

The LEXT4000 LSCM uses a $405 \mathrm{~nm}$ short-wavelength semiconductor laser as the light source, and a surface microscopic image with horizontal resolution can be obtained by scanning the two-dimensional (2D) surface of the sample using the high-precision scanning device. Based on confocal technology, a high-precision stepping motor and focusing device are used to obtain the longitudinal spatial coordinates of each 2D image and focal plane. The 3D shape of the sample surface can be obtained by superimposing the microscopic 

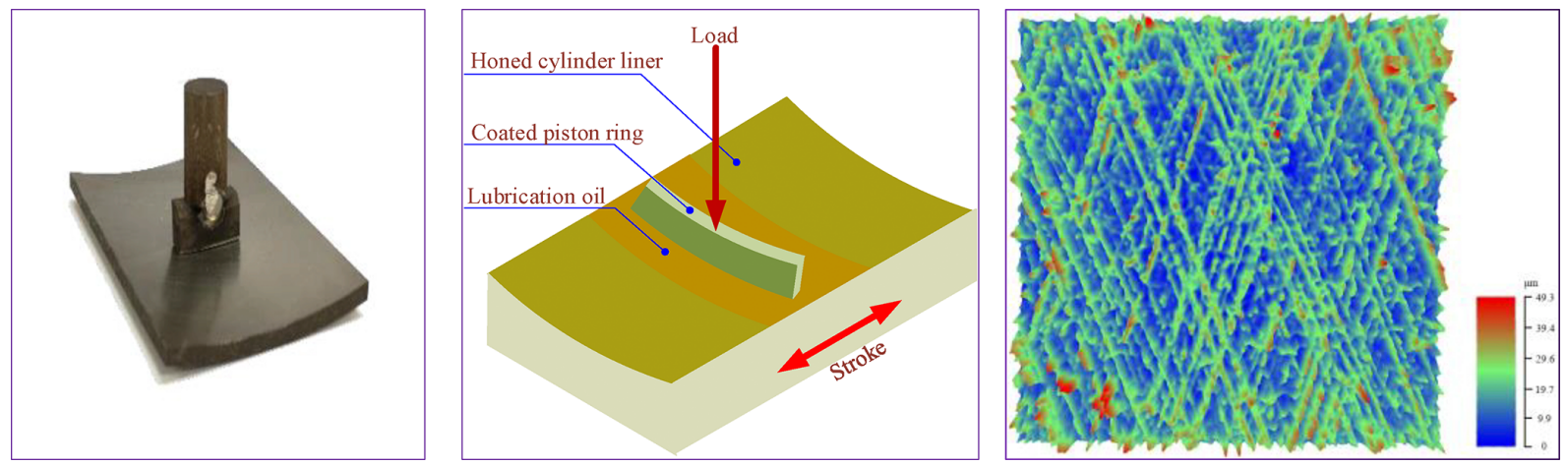

Figure 3. A schematic diagram of the testing process.

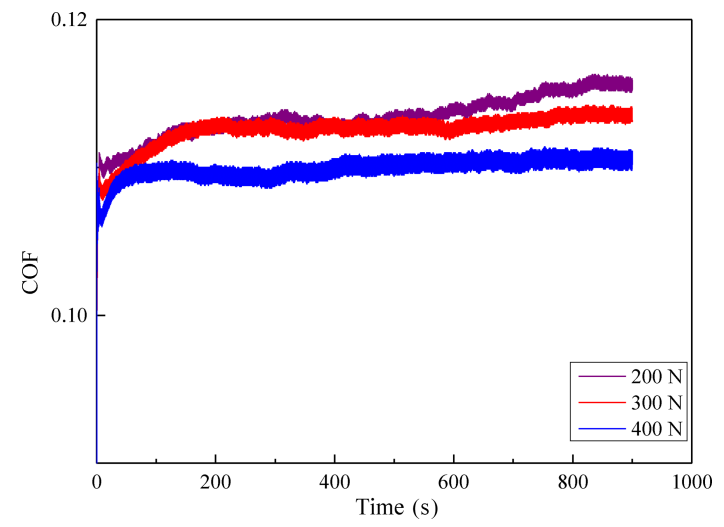

Figure 4. The COF of the cylinder liner under dry lubrication conditions.

image of each focal plane, and the geometric parameters can be obtained by calculating the sampling data. Accurate measurement is the basis of analysis. A 3D LSCM uses a laser beam with a diameter of $0.4 \mu \mathrm{m}$ to scan the surface of the sample; the accuracy of the grating control is $0.8 \mathrm{~nm}$, the horizontal resolution is $0.12 \mu \mathrm{m}$, and the moving accuracy is $10 \mathrm{~nm}$. Therefore, the 3D LSCM is used to collect information on the wear surface. The measurement equipment is shown in Fig. 2.

\subsection{Material preparation}

A boron-phosphorus alloy cast iron cylinder liner is used as the testing sample. For the purpose of testing, the cylinder liner is processed into $43.18 \mathrm{~mm} \times 30.48 \mathrm{~mm}$ slices by wire cutting. A chromium-coated piston ring is used as the ring sample, and the piston ring is processed into $5 \mathrm{~mm} \times 2 \mathrm{~mm}$ slices. Generally, the gap between the cylinder liner and the piston is about $0.2 \mathrm{~mm}$; this can realize the conformal contact between the cylinder liner and the piston ring when the samples are processed into slices. The experimental lubrication oil is CD5W-40, and the sample was washed in anhydrous ethanol with an ultrasonic cleaner for $15 \mathrm{~min}$ before and af- ter the test. The processed piston ring and cylinder liner are shown in Fig. 3.

\section{Results and discussion}

The COF, surface profile, and roughness of the cylinder liner continuously change during the running-in process. The changes in surface topography significantly affect the lubrication and wear of the PRCL system. Due to the poor lubrication of the cylinder liner at TDC, the working condition is complicated, and the wear is relatively higher than in other areas. Using the test rig in Sect. 2, the tribology performance of the honed cylinder liner at TDC is investigated under different operating conditions. The $\mathrm{COF}$, surface roughness, and morphology characteristics are used to characterize the friction and wear, and the evolution of the tribological surface is discussed and summarized. The COF and the wear model can be expressed as follows:

$\mathrm{COF}=\frac{F}{N}$

where $F$ is the friction force, and $N$ is the normal load.

$V=K \frac{N S}{H}$,

where $V$ is the wear volume, $K$ is the wear coefficient, $S$ is the sliding distance, and $H$ is the material hardness.

\subsection{Tribological performance during running-in}

The change in the cylinder liner surface during the runningin process affects the friction performance of the system. The COF, surface roughness and profile are very important to control the lubrication, the friction and the wear. Therefore, in order to reveal the wear performance of the cylinder liner during the running-in process, the relationship between the tribological parameters and the surface topography is investigated based on the wear test. Generally speaking, the mechanical and thermal loads are concentrated at the TDC, and the lubrication oil is depleted or insufficient in the top 

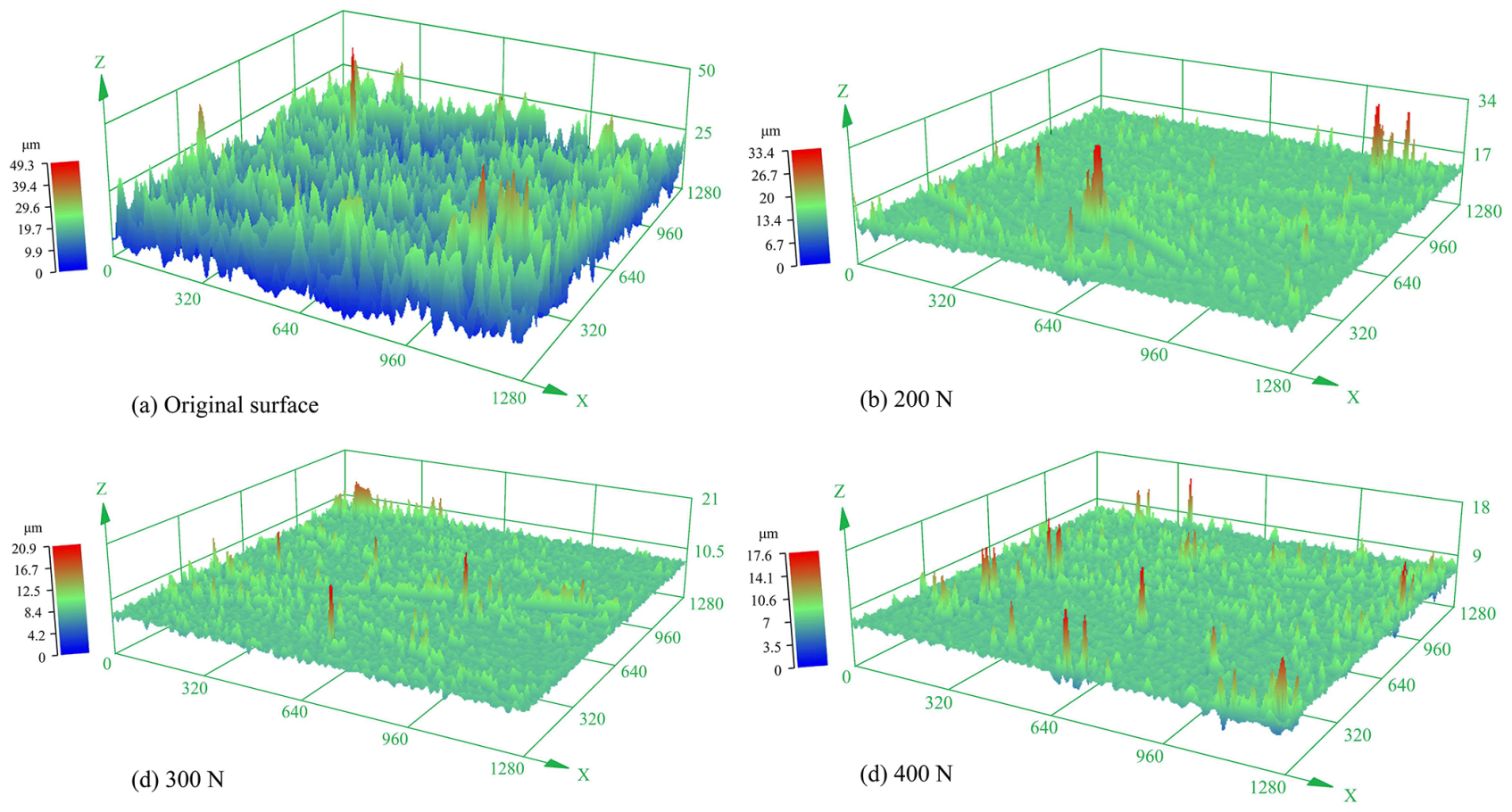

Figure 5. The 3D surface topography of the wear surface under dry friction.

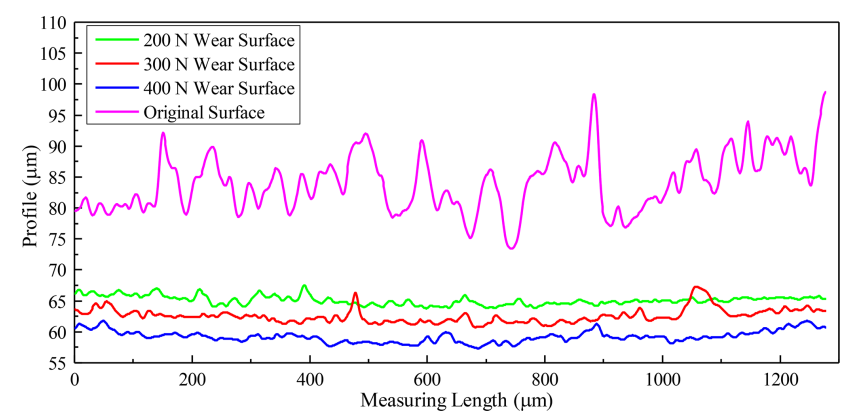

Figure 6. Profile curve of the wear surface under dry friction.

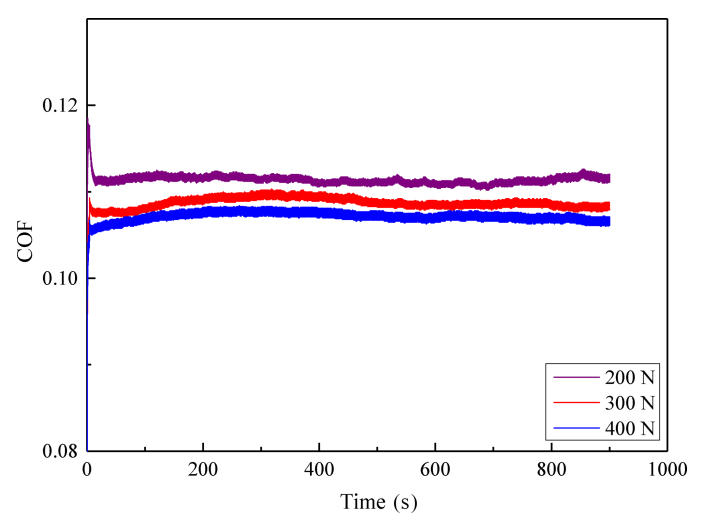

Figure 7. The COF of the cylinder liner under boundary lubrication conditions.

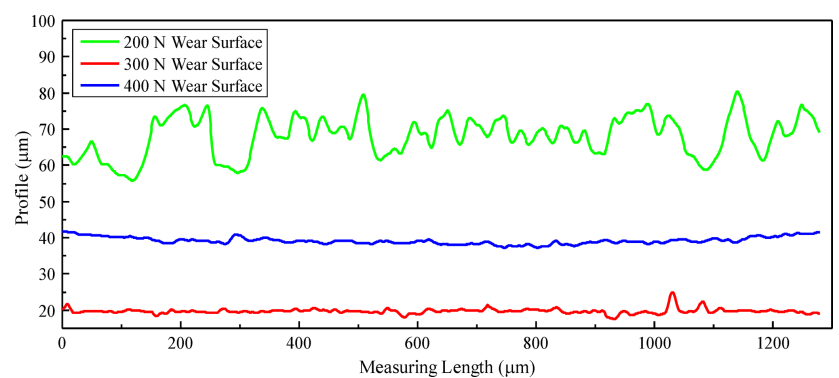

Figure 8. Profile curve of the wear surface under boundary lubrication conditions.

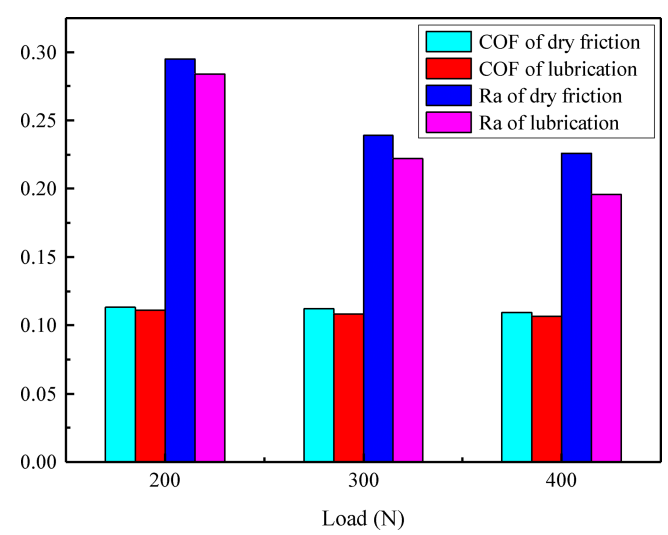

Figure 9. The COF and surface roughness under different lubrication conditions. 


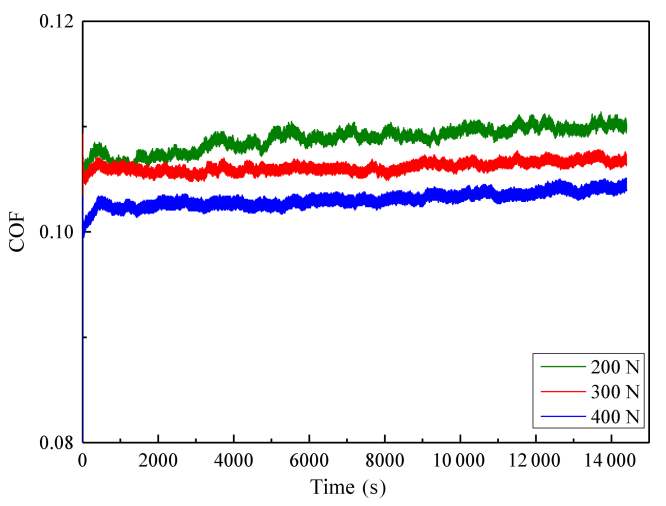

Figure 10. The COF of the cylinder liner under different loads.

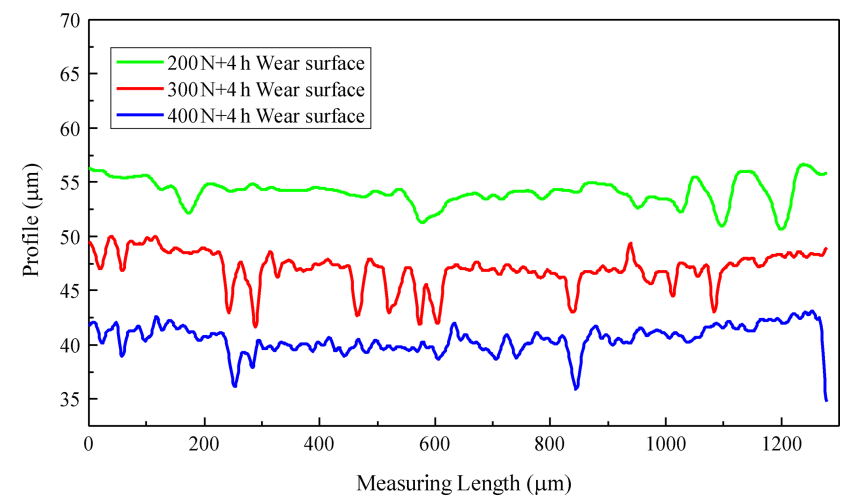

Figure 11. Profile curve of the wear surface under different loads.

region. Thus, the dry and boundary lubrication conditions are considered to investigate the tribological performance of the cylinder liner under different loads for a $15 \mathrm{~min}$ test time. Figure 4 shows the change curve of the COF during the running-in process under dry friction conditions. It can be seen that the COF decreases with an increase in the load (200, 300 and $400 \mathrm{~N}$ with respective contact pressures of 20 , 30 and $40 \mathrm{MPa}$ ). The COF varies little when the load changes from 200 to $300 \mathrm{~N}$, whereas it changes greatly when the load increases to 400 N. From Eq. (2), it can be seen that the wear volume increases with an increase in the load $(\mathrm{N})$; hence, the honing peak of the contact surface is quickly worn off under a heavy load. The influence of surface morphology on the COF has been described in the literature (Grabon et al., 2018). Smoothness is the degree of unevenness on the surface of the testing sample: the lower the surface roughness, the smoother the surface. Therefore, smoothness is used to qualitatively describe the surface quality of the testing sample. Figure 5 shows the 3D surface topography of the wear surface. It can be clearly observed that the surface roughness successively decreases from Fig. 5a to d. Using the LSCM, the 2D surface profile curves under dry lubrication conditions can be measured, as shown in Fig. 6. Compared with the unworn surface, it can be seen that the surface peak heights

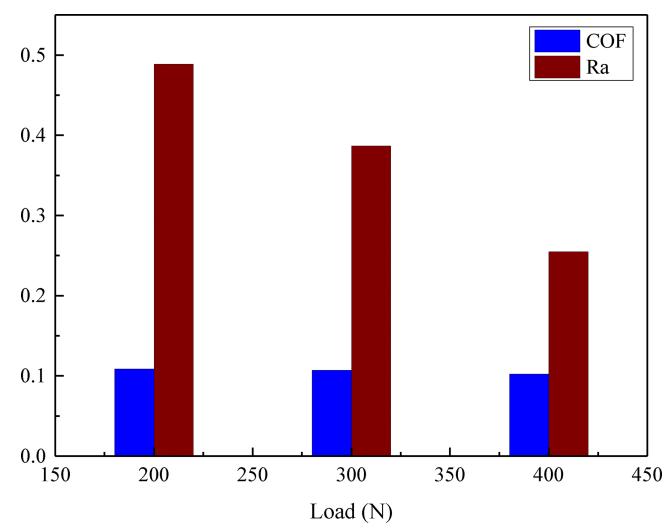

Figure 12. The COF and surface roughness under different loads.

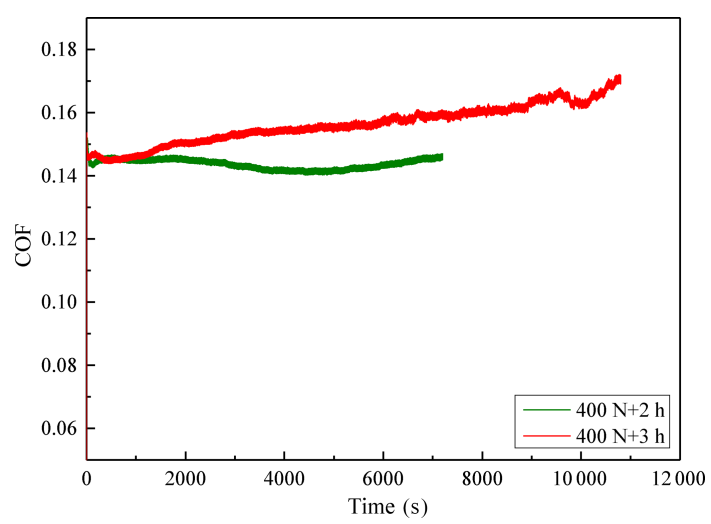

Figure 13. The COF under different lubrication conditions.

were worn off and that the surface of the cylinder liner is smoother.

Full film lubrication can greatly reduce friction and wear. However, due to the poor lubrication of the cylinder liner at TDC, it is generally in a boundary lubrication condition. Therefore, the wear of TDC under boundary lubrication is tested. Figures 7 and 8 show the COF and profile curve of the wear surface under boundary lubrication. Similar to Fig. 4, the COF decreases as the load increases. In Fig. 7, it can be found that the COF is larger than the dry friction at the beginning of the test, and the average COF is smaller than dry lubrication. Similar research can also be referenced in literature (Vrcek et al., 2019). In Fig. 8, it can be seen that the surface topography changes less when the load is small, and the surface topography gradually becomes smoother as the load increases. Figure 9 compares the average COF and surface roughness under different lubrication conditions. It can be seen from Fig. 9 that the COF and surface roughness under boundary lubrication are lower than under dry lubrication conditions. Although the change in the COF is small, the change in the surface roughness is relatively large (Zhang et al., 2018b). 


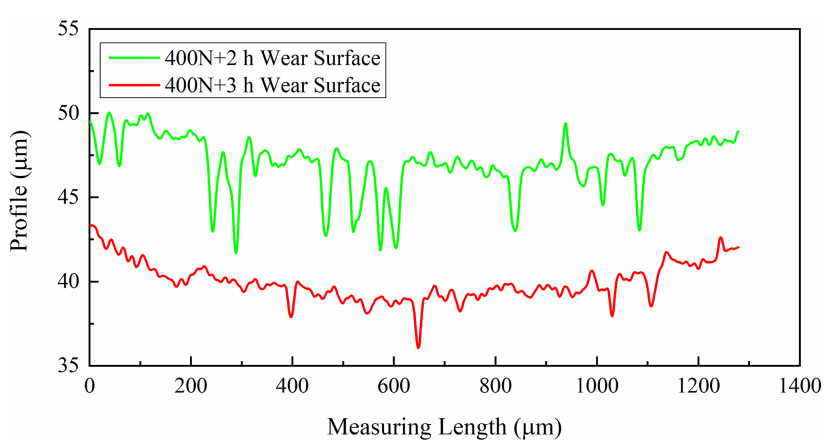

Figure 14. Profile curve under different lubrication conditions.

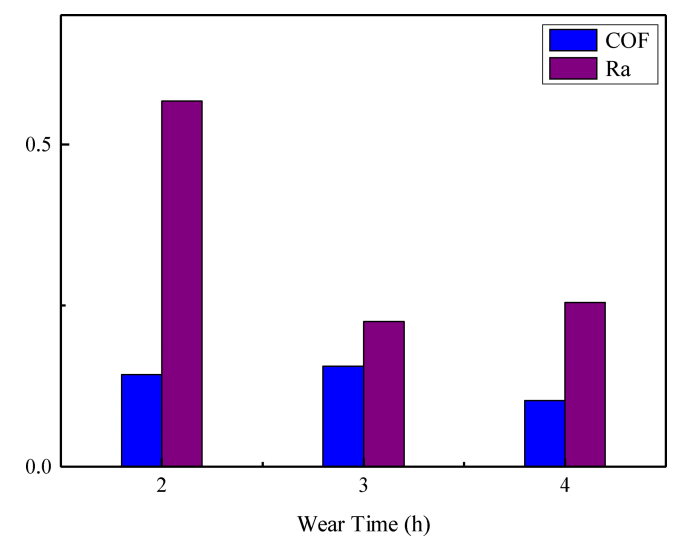

Figure 15. The COF and surface roughness for different wear times.

Running-in can enhance the lubrication and wear performance. During the running-in process, the tribology parameters change with time. Due to the harsh and complex working conditions of the cylinder liner at TDC, the surface roughness decreases significantly. Thus, plateaus are polished during the running-in process (Yousfi et al., 2015; Hu et al., 2017), and the running-in process is vital to reduce wear of the cylinder liner.

\subsection{The effect of different loads under boundary lubrication}

As mentioned earlier, the operating conditions of the PRCL system have a great impact on the tribological parameters. In order to investigate the effect of the load on cylinder liner wear, the relationships between different loads and wear parameters of the cylinder liner at TDC are studied under boundary lubrication conditions. In this section, the testing time was $4 \mathrm{~h}$. Figure 10 shows the COF curves of the cylinder liner under different loads. It can be observed that the $\mathrm{COF}$ decreases as the load increases; hence, with changes in load, the COFs are quite different. In order to illustrate the variation in the surface topography more clearly, the changes in the surface profile of the cylinder liner are shown in Fig. 11.
It can be found that greater loads result in a smaller surface profile value. The main reason for this is that the peaks on the cylinder liner surface are worn down under heavy load under the same operating conditions. In Fig. 12, the average COF and surface roughness under different loads are shown. The figure demonstrates that the COF decreases slowly under the same contact conditions, but the surface roughness changes greatly. Generally, if the running-in process is finished, the surface roughness will remain stable around a certain constant; hence, the surface topography will not change further due to wear over a longer period of time (Pei et al., 2019). Obviously, the cylinder liner is still in the running-in period after $4 \mathrm{~h}$ of wear.

Based on the above analysis, the COF and surface roughness decrease with load increases. The wear rate of the cylinder liner is related to the surface roughness, and the wear resistance of the cylinder liner increases as surface roughness decreases. The load can lead to a significant increase in wear (Macian et al., 2021), and increasing the load can reduce the surface roughness and shorten the running-in period of the system.

\subsection{The effect of lubrication conditions}

The lubrication of the cylinder liner at TDC is prone to insufficiency. In order to analyze the influence of the lubrication state on the surface performance for longer operation periods, the testing is designed using different lubrication conditions and operation times. Figure 13 illustrates the COF under boundary lubrication and dry lubrication conditions, respectively (boundary lubrication for $2 \mathrm{~h}$, dry lubrication for $3 \mathrm{~h}$ ). Compared with dry friction, it can be observed that the COF is relatively small under boundary lubrication conditions (Fig. 13). The COF shows a tendency to increase during the test. The main reason for this is that the abrasive particles caused by wear under dry sliding wear conditions cannot be cleaned away by lubricating oil and remain on the contact surface. Thus, the wear environment of the joint surface becomes worse, and the COF increases. According to the changing characteristics of the COF, it can be concluded that the surface topography changes rapidly under dry lubrication conditions. Figure 14 shows the profile curve under boundary lubrication conditions for $2 \mathrm{~h}$ and dry lubrication conditions for $3 \mathrm{~h}$, respectively. It is observed from Fig. 14 that the surface topography quickly becomes smooth under dry lubrication conditions. In order to further illustrate the changes in the surface quality under different lubrication conditions, Fig. 15 lists the average COF and surface roughness. It can be seen from Fig. 15 that when the load is the same, the lubrication conditions have a great influence on the tribological parameters of the system.

In summary, the results of this work show that wear under dry lubrication conditions is significant during the engine cycle (Zabala et al., 2017). Due to the insufficiency of oil lubrication, the antifriction and antiwear performance of 


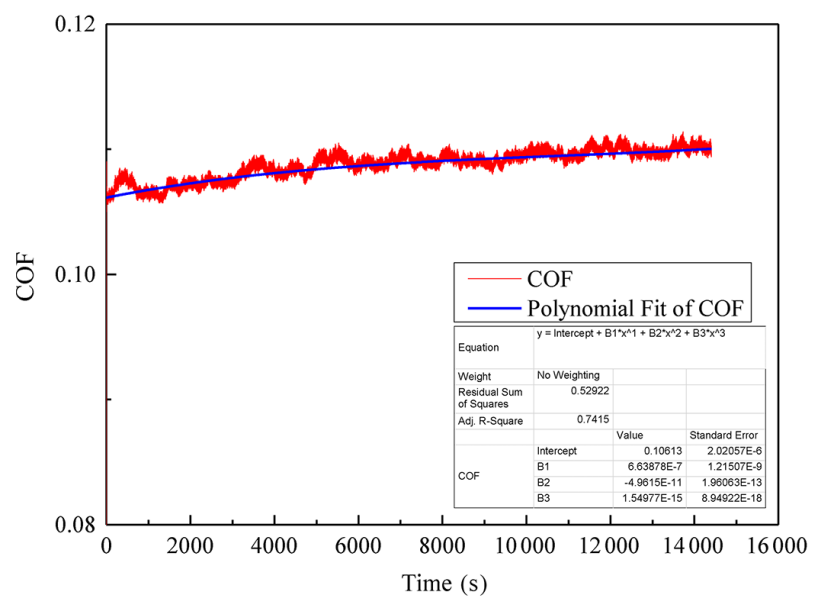

(a) $200 \mathrm{~N}$

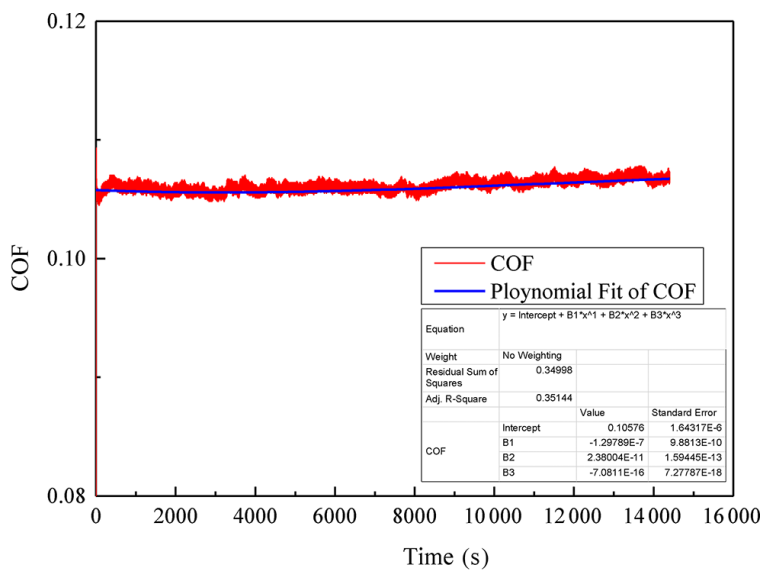

(b) $300 \mathrm{~N}$

Figure 16. The COF evaluation curve after $4 \mathrm{~h}$ of testing under different loads.

the cylinder liner at TDC is weak. The contact surface under boundary lubrication conditions supplies antiwear additives, which are beneficial with respect to better preventing wear. The antiwear performance of the cylinder liner at TDC can be more thoroughly investigated in the future.

\subsection{The COF estimation}

The COF is an important parameter with respect to the tribological performance and is related to the load, speed and lubrication conditions. In general, the COF is usually difficult to predict. In order to reduce the test time and test costs under the same conditions, the COFs are estimated based on test data which included the operating conditions (such as load, speed and lubrication condition). For the observation and analysis of the COF data, the polynomial function method is used to estimate the evolution rule of the COF. The fitting function can be expressed as follows:

$y=a+b x+c x^{3}+d x^{3}$,

where $y$ is the COF; $x$ is the operation time; and $a, b, c$ and $d$ are the respective polynomial coefficients.

Figure 16a and $\mathrm{b}$ show the evaluation curve of the COF after $4 \mathrm{~h}$ of testing under different loads (200 and $300 \mathrm{~N})$. It can be observed that the estimated curve is consistent with the testing value, and the standard error is very small. Table 2 lists the evaluated parameters of the COF under different loads, and the polynomial prediction method can obtain the average path and realize the real-time prediction of the COF. Using the estimated parameters, the COF can be predicted in the future, and the monitoring cost can be reduced. As the method is similar, the COF curve with a $400 \mathrm{~N}$ load is not shown in this paper.

\section{Conclusion}

In a piston ring-cylinder liner system, the friction and wear lead to more than $50 \%$ of the total frictional losses. The TDC is the most seriously worn part of the cylinder liner during the running-in process; thus, it is vitally important to investigate the tribological properties of this region. To this end, friction and wear tests were designed, using on the UMT TriboLab multifunction friction wear tester, under different operating conditions. The changes in the COF, roughness and surface profile were analyzed during the running-in process. Meanwhile, in order to monitor the COF of the cylinder liner in real time, a prediction method was proposed.

The COF decreases continuously with an increase in the load and with time at the beginning of the running-in process; as the load increases, the profile peak of the honed cylinder liner wears off rapidly. Meanwhile, the surface morphology and profile curve are also continuously reduced, and the friction and wear change more quickly under dry lubrication conditions. After $4 \mathrm{~h}$ of testing, the change trend in the COF and surface quality is the same as the initial stage under boundary lubrication conditions. However, due to prolonged wear, the changes in the surface roughness are relatively large. Under dry lubrication conditions, the COF shows a tendency to increase over the test period, and the antifriction and antiwear are greatly reduced. The polynomial fitting method can predict the COF under different loads with small errors.

Data availability. All of the data used in this paper can be obtained from the corresponding author upon request.

Author contributions. JK was responsible for writing the draft of the paper; YL and YZ were responsible for overseeing the writing 
process and developing the framework of the paper; BZ, CJ and PL were responsible for figure processing; and HL was responsible for editing.

Competing interests. The contact author has declared that neither they nor their co-authors have any competing interests.

Disclaimer. Publisher's note: Copernicus Publications remains neutral with regard to jurisdictional claims in published maps and institutional affiliations.

Acknowledgements. This work has been supported by the National Natural Science Foundation of China (grant nos. 51775428 and 52075438), the Key Research and Development Program of Shaanxi Province of China (grant no. 2020GY-106) and the Open Project of State Key Laboratory for Manufacturing Systems Engineering (grant no. sklms2020010).

Financial support. This research has been supported by the National Natural Science Foundation of China (grant nos. 51775428 and 52075438), the Key Research and Development Program of Shaanxi Province of China (grant no. 2020GY-106) and the Open Project of State Key Laboratory for Manufacturing Systems Engineering (grant no. sklms2020010).

Review statement. This paper was edited by Bahman Azarhoushang and reviewed by two anonymous referees.

\section{References}

Asnida, M., Hisham, S., Awang, N. W., Amirruddin, A. K., Noor, M. M., Kadirgama, K., Ramasamy, D., Najafi, G., and Tarlochan, F.: Copper (II) oxide nanoparticles as additve in engine oil to increase the durability of piston-liner contact, Fuel, 212, 656667, https://doi.org/10.1016/j.fuel.2017.10.002, 2018.

Awang, N. W., Ramasamy, D., Kadirgama, K., Najafi, G., and Sidik, N. A. C.: Study on friction and wear of Cellulose Nanocrystal (CNC) nanoparticle as lubricating additive in engine oil, Int. J. Heat. Mass. Tran., 131, 1196-1204, https://doi.org/10.1016/j.ijheatmasstransfer.2018.11.128, 2019.

Babu, P. V., Syed, I., and Benbeera, S.: Experimental investigation on effects of positive texturing on friction and wear reduction of piston ring/cylinder liner system, Mater. Today-Proc., 24, 11121121, https://doi.org/10.1016/j.matpr.2020.04.424, 2020.

Biberger, J. and Fuber, H. J.: Development of a test method for a realistic, single parameter-dependent analysis of piston ring versus cylinder liner contacts with a rotational tribometer, Tribol. Int., 113, 111-124, https://doi.org/10.1016/j.triboint.2016.10.043, 2017.

Burkinshaw, M., Neville, A., Morina, A., and Sutton, M.: The lubrication of both aluminium-silicon and model silicon surfaces with calcium sulphonate and an organic antiwear additive, Tribol.
Int., 67, 211-216, https://doi.org/10.1016/j.triboint.2013.07.006, 2013.

Ferreira, R., Almeida, R., Carvalho, O., Sobral, L., Carvalho, S., and Silva, F.: Influence of a DLC coating topography in the piston ring/cylinder liner tribological performance, J. Manuf. Process., 66, 483-493, https://doi.org/10.1016/j.jmapro.2021.04.044, 2021.

Grabon, W., Pawlus, P., Wos, S., Koszela, W., and Wieczorowski, M.: Effects of cylinder liner surface topography on friction and wear of liner-ring system at low temperature, Tribol. Int., 121, 148-160, https://doi.org/10.1016/j.triboint.2018.01.050, 2018.

Guo, Z. W., Yuan, C. Q., Liu, P., Peng, Z. X., and Yan, X. P.: Study on influence of cylinder liner surface texture on lubrication performance for cylinder liner-piston ring components, Tribol. Lett., 51, 9-23, https://doi.org/10.1007/s11249-013-0141-y, 2013.

Hamid, Y., Usman, A., Afaq, S. K., and Park, C. W.: Numeric based low viscosity adiabatic thermo-tribological performance analysis of piston-skirt liner system lubrication at high engine speed, Tribol. Int., 126, 166-176, https://doi.org/10.1016/j.triboint.2018.05.022, 2018.

Hu, Y., Meng, X. H., and Xie, Y. B.: A computationally efficient mass-conservation-based, two-scale approach to modeling cylinder liner topography changes during running-in, Wear, 386, 139 156, https://doi.org/10.1016/j.wear.2017.06.014, 2017.

Javeed, A., John, B., and Mana, A. P.: Tribological performance of engine oil with graphene oxide nano additives on cylinder liner honing surface at high contact pressure, Mater. Today-Proc., 45, 4008-4011, https://doi.org/10.1016/j.matpr.2020.09.636, 2021.

Kim, E. S., Kim, S. M., and Lee, Y. Z.: The effect of plateau honing on the friction and wear of cylinder liners, Wear, 400, 207-212, https://doi.org/10.1016/j.wear.2017.09.028, 2018.

Kumar, V., Sinha, S. K., and Agarwal, A. K.: Wear evaluation of engine piston rings coated with dual layer hard and soft coatings, J. Tribol., 141, 1-24, https://doi.org/10.1115/1.4041762, 2018.

Liu, C., Lu, Y. J., Wang, P., Zhang, Y. F., Zhang, Y. G., and Müller, N.: Numerical analysis of the effects of compression ring wear and cylinder liner deformation on the thermal mixed lubrication performance of ring-liner system, Mech. Ind., 19, 1-14, https://doi.org/10.1051/meca/2018015, 2018.

Liu, C., Lu, Y. J., Zhang, Y. F., Li, S., Kang, J. X., and Müller, N.: Numerical study on the tribological performance of ring/liner system with consideration of oil transport, J. Tribol., 141, 1-16, https://doi.org/10.1115/1.4040510, 2019.

Liu, L., Yang, C., and Sheng, Y. Y.: Wear model based on real-time surface roughness and its effect on lubrication regimes, Tribol. Int., 126, 16-20, https://doi.org/10.1016/j.triboint.2018.05.010, 2018.

Ma, S. Q., Chen, W. B., Li, C. D., Jin, M., Huang, R. X., and Xu, J. J.: Wear properties and scuffing resistance of the $\mathrm{Cr}-\mathrm{Al}_{2} \mathrm{O}_{3}$ coated piston rings: The effect of convexity position on barrel surface, J. Tribol., 141, 1-25, https://doi.org/10.1115/1.4041215, 2019.

Macian, V., Tormos, B., Bermudez, V., and Bastidas, S.: Development of a floating liner test rig and lubrication model for the study of the piston compression ring friction force under fully flooded and starved lubrication, Tribol. Int., 160, 1-14, https://doi.org/10.1016/j.triboint.2021.107034, 2021.

Michalski, J. and Wos, P.: The effect of cylinder liner surface topography on abrasive wear of piston-cylinder 
assembly in combustion engine, Wear, 271, 582-589, https://doi.org/10.1016/j.wear.2010.05.006, 2011.

Musmar, S. A., Alrousan, A., and Tlili, I.: Effect of cylinder-liner rotation on wear rate: An experimental study, Heliyon, 5, 1-7, https://doi.org/10.1016/j.heliyon.2019.e02065, 2019.

Obert, P., Müller, T., Füßer, H. J., and Bartel, D.: The influence of oil supply and cylinder liner temperature on friction, wear and scuffing behavior of piston ring cylinder liner contacts-A new model test, Tribol. Int., 94, 306-314, https://doi.org/10.1016/j.triboint.2015.08.026, 2016.

Ogut, H., Oguz, H., Aydın, F., Ciniviz, M., and Deveci, H.: The investigation of the use of plant-based wild mustard and boron doped oil as engine lubrication oil in diesel engines, Renew. Energ., 136, 79-83, https://doi.org/10.1016/j.renene.2018.12.117, 2019.

Pei, X., Pu, W., Zhang, Y., and Huang, L.: Surface topography and friction coefficient evolution during sliding wear in a mixed lubricated rolling-sliding contact, Tribol. Int., 137, 303-312, https://doi.org/10.1016/j.triboint.2019.05.013, 2019.

Sun, J., Zhang, X., Zhu, J. X., Gao, Y. M., Wang, H., Zhao, X. Y., and Teng, Q.: On the lubrication characteristics of piston ring under different engine operation conditions, Ind. Lubr. Tribol., 72, 101-108, https://doi.org/10.1108/ILT-06-2019-0220, 2019.

Tomanik, E., Mansori, M. E., Souza, R., and Profito, F.: Effect of waviness and roughness on cylinder liner friction, Tribol. Int., 120, 547-555, https://doi.org/10.1016/j.triboint.2018.01.012, 2018.

Usman, A. and Park, C. W.: Modeling and simulation of frictional energy loss in mixed lubrication of a textured piston compression ring during warm-up of spark ignition engine, Int. J. Engine Res., 18, 293-307, https://doi.org/10.1177/1468087416656676, 2016.

Usman, A. and Park, C. W.: Numerical investigation of tribological performance in mixed lubrication of textured piston ring-liner conjunction with a non-circular cylinder bore, Tribol. Int., 105, 148-157, https://doi.org/10.1016/j.triboint.2016.09.043, 2017.
Vrcek, A., Hultqvist, T., Baubet, Y., Björling, M., Marklund, P., and Larsson, R.: Micro-pitting and wear assessment of engine oils operating under boundary lubrication conditions, Tribol. Int., 129, 338-346, https://doi.org/10.1016/j.triboint.2018.08.032, 2019.

Walker, A. C., Cinti, S., Kamps, T. J., Mitchell-Smith, J., and Clare, A. T.: Influence of contact area on the sliding friction and wear behaviour of an electrochemical jet textured Al-Si alloy, Wear, 426, 1336-1344, https://doi.org/10.1016/j.wear.2019.01.008, 2019.

Yousfi, M., Mezghani, S., Demirci, I., and El-Mansori, M.: Smoothness and plateauness contributions to the running-in friction and wear of stratified helical slide and plateau honed cylinder liners, Wear, 332, 1238-1247, https://doi.org/10.1016/j.wear.2014.11.011, 2015.

Zabala, B., Igartua, A., Fernandez, X., Priestner, C., Ofner, H., Knaus, O., Abramczuk, M., Tribotte, P., Girot, F., Roman, E., and Nevshupa, R.: Friction and wear of a piston ring/cylinder liner at the top dead centre: Experimental study and modelling, Tribol. Int., 106, 23-33, https://doi.org/10.1016/j.triboint.2016.10.005, 2017.

Zhang, Y. Z, Kovalev, A., and Meng, Y. G.: Combined effect of boundary layer formation and surface smoothing on friction and wear rate of lubricated point contacts during normal running-in processes, Friction, 6, 274-288, https://doi.org/10.1007/s40544018-0228-4, 2018a.

Zhang, Y. Z., Kovalev, A., Hayashi, N., Nishiura, K., and Meng, Y. G.: Numerical prediction of surface wear and roughness parameters during running-in for line contacts under mixed lubrication, J. Tribol., 140, 1-13, https://doi.org/10.1115/1.4039867, 2018b. 